\title{
Acute Bilateral Opercular Strokes Causing Loss of Emotional Facial Movements
}

\author{
Valerie L. Sim, Alan Guberman, Matthew J. Hogan
}

\begin{abstract}
The classic anterior opercular syndrome of Foix-Chavany-Marie presents with loss of voluntary facial, pharyngeal, lingual, and mastication movements, with preservation of emotional and automatic movements. Most commonly, sequential strokes affecting bilateral opercula cause this syndrome. The inverse clinical presentation, with selective loss of emotional facial movements, has only rarely been reported, and is less well-localized. Case report: We report a case of selective loss of emotional facial movements which resulted from bilateral acute infarcts. No etiology was discovered, and the syndrome was reversible. Discussion: The available literature, and findings in this case, suggest that voluntary and automatic facial movements have distinct pathways, and damage to the insula bilaterally may lead to the selective loss of emotional facial movements. The clinical presentation of this inverse automatic/voluntary dissocation needs to be recognized as a rare syndrome with bilateral localization, so that patients at higher risk of further stroke can quickly be identified.
\end{abstract}

RÉSUMÉ: Accidents vasculaires operculaires aigus bilatéraux causant la perte des mouvements faciaux émotionnels. Dans le syndrome operculaire antérieur classique (SOA) de Foix-Chavany-Marie, on observe une perte des mouvements volontaires de la face, du pharynx, de la langue et de la mastication et une préservation des mouvements émotionnels et automatiques. Ce syndrome résulte la plupart du temps d'accidents vasculaires cérébraux consécutifs affectant les opercules. Un tableau clinique inverse, soit une perte sélective des mouvements faciaux émotionnels, a rarement été rapporté et la pathologie sous-jacente est mal localisée. Cas Clinique: Nous rapportons un cas de perte sélective des mouvements faciaux émotionnels suite à des infarctus aigus bilatéraux. Aucune étiologie n'a pu être mise en évidence et le syndrome a été réversible. Discussion: Une revue de la littérature et les observations relatives à ce cas clinique suggèrent que les mouvements faciaux volontaires et automatiques empruntent des voies distinctes et que des dommages bilatéraux à l'insula peuvent causer une perte sélective des mouvements faciaux émotionnels. Le tableau clinique de cette dissociation automatique/volontaire inverse doit être reconnu comme un syndrome rare ayant une localisation bilatérale afin que les patients à haut risque d'accidents vasculaires cérébraux subséquents soient identifiés rapidement.

Can. J. Neurol. Sci. 2005; 32: 119-121

Loss of voluntary facial, pharyngeal, lingual, and mastication movements, with preservation of emotional and automatic movements is the hallmark of the bilateral anterior opercular syndrome (AOS) of Foix-Chavany-Marie, although rarely the inverse occurs. Sequential strokes affecting both hemispheres or bilateral acute infarcts have been reported to cause the syndrome. We report a case of this syndrome, due to ischemia, which showed inverse dissociation of facial movements and which was reversible.

\section{Case Report}

A 50-year-old right-handed female scientist had a brief choking episode while drinking water before bedtime. The next morning she awoke with a mild frontal headache. An hour later, while in the shower, she had the sensation that her voice sounded "as if listening to myself on a tape recorder, with a delay". She had trouble doing up her buttons and a zipper, and could not figure out how to use the microwave. She drove to work without difficulty but felt generally tired and unwell. At work, she again felt that she was not hearing her voice normally, although other people sounded normal. By lunchtime, her colleagues commented on her blank facial expression and some mild dysarthria. There were no difficulties in comprehension and she was still able to give an oral presentation. In the evening she began drooling and noticed difficulty swallowing. By the next morning, her dysarthria and drooling were much worse and her headache was still present. She found both hands "clumsy" and began dropping things. She also felt she had less sensation in her hands and over her face. Her handwriting became difficult to read and she made spelling mistakes, at times omitting letters. At this point, she presented to the emergency department.

From the Department of Neurology, The Ottawa Hospital, Ottawa, ON Canada ReCEIVED APRIL 2, 2004. ACCEPTEDINFINALFORM July 27, 2004.

Reprint requests to: Alan Guberman, The Ottawa Hospital, General Campus, Neurology Department, 501 Smyth Road, Ottawa, ON, K1H 8L6 Canada. 
She was generally healthy but had started oral contraceptives for fibroids ten days previously. She had taken birth control pills for three or four months at the age of 23 until she awoke in the middle of the night with a migrainous headache, speaking "gibberish" and having trouble finding words. She did not have any other migraine headaches, just occasional zigzag visual scintillations. Over the past year she developed daily scintillations lasting several minutes. She took no other medications, did not smoke, and drank half a bottle of wine a day. She had no history of heart disease, diabetes, hypercholesterolemia, hypertension, miscarriage, or deep vein thrombosis. There was one family member who had a stroke at the age of 50 .

At the time of presentation, her blood pressure was 118/60, heart rate was regular and she was alert and oriented. She was fluent but dysarthric. Naming, repetition and comprehension were intact and there were no paraphasic errors. Pupillary reaction, visual fields, and eye movements were normal. She had limited bilateral lower facial movement during speech and spontaneous activity, but normal voluntary facial movement with formal testing. Hearing was normal. Tongue and palate movements were normal and she could repeat consonants, but she had no gag reflex and was drooling. Sensation to pinprick and cold were decreased over the face and arms compared to the legs. Vibration was intact. Her motor exam was unremarkable, all reflexes were 2+ bilaterally, and toes were downgoing. No coordination deficits were elicited on formal exam, but she had mild clumsiness when trying to put on her shoes. Gait was normal. Her general exam, including the cardiovascular system, was unremarkable.

Computed tomography and magnetic resonance imaging with diffusion weighted images demonstrated acute infarcts in both insulae, in the right superior temporal gyrus/inferior parietal lobule, and in bilateral centrum semiovale (Figure). Both a magnetic resonance venogram and a magnetic resonance angiogram of intra- and extracranial vessels were normal. Investigations, including a transesophageal echocardiogram and a hypercoaguable and vasculitic screen, were unremarkable. Her chest X-ray and electrocardiogram were normal.

She was given intravenous heparin for a presumed cardioembolic source, until results from echocardiograms were available. Her deficits resolved completely over the next few days, and she was discharged home six days after admission, on a dipyridamole-low dose acetylsalicylic acid combination $\left(\right.$ Aggrenox $\left.^{\mathrm{R}}\right)$. She was taken off oral contraceptives. At two years follow-up she was asymptomatic.

\section{Discussion}

Anterior opercular syndrome, with selective loss of voluntary facial movements, usually results from bilateral anterior perisylvian lesions. Decreased opercular perfusion occurs in these patients, ${ }^{1}$ and acute right opercular ischemia, following a previous left middle cerebral artery infarct, can cause AOS. ${ }^{2}$ However, there are cases resulting from left middle cerebral artery territory infarction plus right corona radiata infarction, ${ }^{3}$ bilateral deep lacunar infarcts plus a right opercular lesion, ${ }^{1}$ and bilateral internal capsule infarcts (medial, genu, or rostral posterior $)^{4}$ without opercular involvement. ${ }^{5}$ Two cases of possible unilateral lesions causing AOS have been discussed in a previous review. ${ }^{6}$

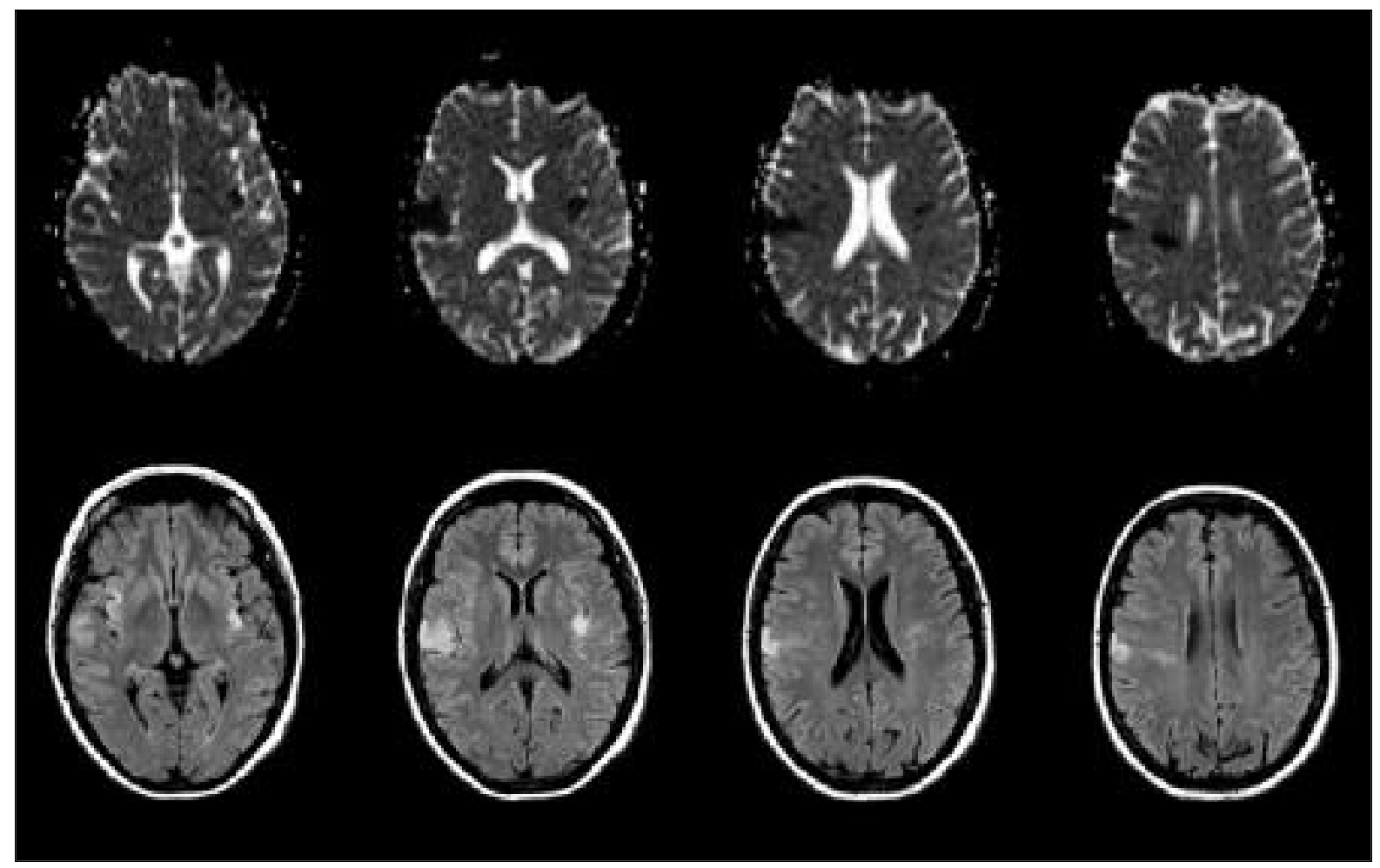

Figure: Axial MRI sequences demonstrating bilateral insular, right superior temporal gyrus/inferior parietal lobule, and bilateral centrum semiovale acute infarcts (top: ADC, bottom: FLAIR). 
The inverse anterior opercular syndrome, with selective loss of emotional facial movements, has rarely been reported. These cases include brain metastases in both Rolandic opercula, ${ }^{7}$ an intrapontine lesion, ${ }^{8}$ and surgical removal of the Penfield supplementary motor area. ${ }^{8}$ Our case presented with acute bilateral infarcts involving the inferior posterior half of the right insular cortex, the superior posterior third of the left insular cortex, including the transverse temporal convolutions (areas 41 and 42; auditory area), the right superior temporal gyrus/inferior parietal lobule, the right centrum semiovale, and small regions of the left centrum semiovale (Figure). Of these areas, the damaged insula most likely caused selective emotional pathway dysfunction, as a similar case was seen with metastases to the opercula. ${ }^{7}$

Two other symptoms in this case merit localization. Our patient heard her voice "...as if listening to myself on a tape recorder, with a delay". Damage to the transverse temporal convolutions (areas 41 and 42; auditory area) and the right superior temporal gyrus/inferior parietal lobule likely caused this altered sound perception, because these areas, among others, are activated during sound recognition and localization. ${ }^{9}$ The symptoms of drooling and trouble swallowing can be attributed to the right insular lesion, as this area is active during swallowing. ${ }^{10}$

Classic AOS may result from tumours, trauma, encephalitis, neurodegenerative etiologies, or a congenital perisylvian syndrome, ${ }^{6}$ but strokes are the most common cause. Usually, unilateral acute ischemia follows a previous contralateral stroke, ${ }^{6}$ but bilateral acute infarcts do occur in one to six percent of stroke patients. ${ }^{11-13}$ Such patients are usually younger and more likely to have rarer risk factors such as coagulopathies, systemic disorders and rare nonatherosclerotic arteriopathies. ${ }^{11,13}$ Elevated fibrinogen level or hematocrit is significantly associated with bilateral hemisphere involvement ${ }^{11}$ and venous infarction and hypotensive borderzone infarcts must be considered. Sometimes no cause is identified, ${ }^{11,13}$ as in our case (except for possibly oral contraceptives).

The presenting features of bilateral infarcts are important to recognize, but the clinical suspicion of multiple infarcts, prior to imaging, has been very low in most reported cases. ${ }^{12,13}$ In AOS, patients lose voluntary control of their facial, pharyngeal, lingual, mastication, and sometimes ocular muscles, but preserve emotional and automatic functions of these same muscles such as yawning and blinking spontaneously. ${ }^{14}$ Patients with the inverse (our case) can move to command, but have reduced facial expressiveness and little or no emotional or spontaneous movement. In contrast, patients with oral-buccal-lingual apraxia will have more difficulty with more complex praxic tasks, such as blowing a kiss, while patients with AOS cannot do even simple imitative tasks like opening the mouth. Bulbar palsy is differentiated by its lack of both voluntary and automatic movement. Pseudobulbar palsy is associated with emotional lability and an increased gag reflex, while the gag reflex is often absent in AOS. ${ }^{14}$

Voluntary and automatic facial movements have distinct pathways. Damage to the insula bilaterally may lead to the selective loss of emotional facial movements. This inverse of the traditional AOS automatic/voluntary dissocation, needs to be recognized as a rare syndrome with bilateral localization. While the etiology of acute bilateral infarction in cases such as ours is not always clear, this syndrome is potentially reversible.

\section{REFERENCES}

1. Ann MY, Liu OK, Wu YL. Foix-Chavany-Marie syndrome. Chung Hua i Hsueh Tsa Chih Chin Med J 2001; 64(9): 540-544.

2. Szabo K, Gass A, Robmanith C, Hirsch JG, Hennerici MG. Diffusion and perfusion weighted MRI demonstrates synergistic lesions in acute ischemic Foix-Chavany-Marie Syndrome. J Neurol 2002; 249(12): 1735-1737.

3. Kobayashi S, Kunimoto M, Takeda K. A case of Foix-ChavanyMarie syndrome and crossed aphasia after right corona radiata infarction with history of left hemispheric infarction. Rinsho Shinkeigaku 1998; 38(10-11): 910-914.

4. Besson G, Bogousslavsky J, Regli F, Maeder P. Acute Pseudobulbar or Suprabulbar Palsy. Arch Neurol 1991;48: 501-507.

5. Sztymirska D, Jedrzejowska H. Foix-Chavany-Marie syndrome. Neurol Neurochir Pol 1998; 32(1): 171-176.

6. Weller M. Anterior opercular cortex lesions cause dissociated lower cranial nerve palsies and anarthria but no aphasia: Foix-ChavanyMarie syndrome and "automatic voluntary dissociation" revisited. J Neurol 1993; 240(4): 199-208.

7. Campello I, Velilla I, Lopez-Lopez A, et al. Biopercular lesion with inverse dissociation. Rev Neurol 1995; 23(123): 1056-1058.

8. Laplane D, Orgogozo JM, Meininger V, Degos JD. Facial paralysis with inverse autonomic-voluntary dissociation from a frontal lesion. Cortical origin. Relation to supplementary motor area. Rev Neurol 1976; 132(10): 725-734.

9. Min WK, Park KK, Kim YS, et al. Atherothrombotic middle cerebral artery territory infarction: topographic diversity with common occurrence of concomitant small cortical and subcortical infarcts. Stroke 2000; 31(9): 2055-2061.

10. Maeder PP, Meuli RA, Adriani M, et al. Distinct pathways involved in sound recognition and localization: a human fMRI study. Neuroimage 2001; 14: 802-816.

11. Martin RE, Goodyear BG, Gati JS, Menon RS. Cerebral cortical representation of automatic and volitional swallowing in humans. J Neurophysiol 2001; 85(2): 938-950.

12. Roh JK, Kang DW, Lee SH, Yoon BW, Chang KH. Significance of acute multiple brain infarction on diffusion-weighted imaging. Stroke 2000; 31(3): 688-694.

13. Bogousslavsky J, Bernasconi A, Kumral E. Acute multiple infarction involving the anterior circulation. Arch Neurol 1996; 53: 50-57.

14. Mao C-C, Coull BM, Golper LAC, Rau MT. Anterior operculum syndrome. Neurology 1989; 39: 1169-1172. 